\title{
Investigating the School Teacher's Preparation in Mathematics Pedagogy in Ukraine
}

\author{
N. A. Tarasenkova *, I. A. Akulenko \\ Department of Mathematics and Methods of Teaching Mathematics, Education and Research Institute of Physics, Mathematics and \\ Computer Information Systems, Bohdan Khmelnytsky National University at Cherkasy, Ukraine
}

Copyright (C) 2015 Horizon Research Publishing. All rights reserved.

\begin{abstract}
Teacher education has become an area of considerable interest among policymakers in many countries over recent years. Teacher's knowledge and skills in qualified teaching is of great importance. The main purpose was to study the level and depth of the school mathematics and related teaching knowledge attained by prospective Ukrainian secondary teachers. Some analyses of the study results of prospective Ukrainian secondary teachers are given in the article.
\end{abstract}

Keywords Prospective Teachers, Teacher's Preparation and Training in Mathematics, Mathematics Pedagogy

\section{Introduction}

The work associated with teacher preparation as well as experience gained in many of IEA's studies, such as TIMSS, led to a request for an in-depth study of teacher preparation and training, particularly in terms of the subject area in mathematics. The first IEA study of teacher preparation and training of primary and middle secondary mathematics teachers (TEDS-M 2008) was focused on how teachers are prepared to teach mathematics in primary and middle secondary schools. It is empirical cross-national study based on probability samples that analyzed how educational systems in different countries (Botswana, Canada, Chile, Chinese Taipei, Georgia, Germany, Malaysia, Norway, Oman, Philippines, Poland, Russian Federation, Singapore, Spain, Switzerland (German-speaking cantons), Thailand, and United States) prepare mathematics teachers. It also identified the explicit and implicit expectations for what they should know and be able to do as a result of this preparation.

Methodological reviews $[2 ; 3 ; 4]$ by the IEA Technical Executive Group were issued.

Although Ukraine wasn't involved in the above mentioned project, a similar study was held in this country. The study was designed on the assembled knowledge and experience offered by experts on international monitoring investigations: G. S. Kovaleva, L. O. Denishcheva, T. A. Koreshkova, Y. A. Semeniachenko, and N. V. Sheveliova [1], M. T. Tatto, J. Schwille, S. Senk, K. Bankov, M. Rodriguez, M. Reckase, L. Ingarson, R. Peck, R. Rowley [3]. The investigation was aimed at 1) determining the level of future Mathematics teachers' preparation for teaching the subject matter using preliminary selected Mathematics teacher's professional competences that reflect the specific features of his activity; 2) determining future teachers' core values, beliefs and relations that define their personality position in relation to their future professional activity.

The analyses of the studying Ukrainian future math teachers' beliefs about the level of their preparation for prospective professional activities were given in [8]. The measurement analysis of students' value beliefs with the help of the methods proposed in the TEDS- M project (the beliefs about the nature of mathematics; beliefs about learning mathematics and students' mathematics abilities; students' beliefs about their preparation level for professional activity) were compared with the results of similar study conducted in Russia.

Another dimension of the study was the level of future Mathematics teachers' readiness for teaching subject matter using Mathematics teacher's professional competences that are preliminary selected to reflect the specific features of the activity. The main purpose was to study the level and depth of the mathematics and related teaching knowledge accumulated and acquired by prospective Ukrainian secondary teachers.

\section{Materials and Methods}

The research was targeted on students - future teachers who are in their final year of training before they are eligible to become practicing teachers of mathematics in secondary school. The task was to measure the intended and achieved knowledge of mathematics, mathematics pedagogy and general knowledge for teaching of future teachers in their last year in the sampled teacher education programs. To analyze the situation with the current training in math 
teaching methodology there were conducted some tests. The 537 students in their final year majoring in math at pedagogical universities participated in the study. To prove the result validity the 116 young professionals - newly qualified school math teachers-went through this test too.

\subsection{Literature Overview}

An international project of quality monitoring of Mathematics teachers training TEDS-M (Teacher Education and Development Study in Mathematics 2006 - 2009 [3]) formed a basis for materials and methods in this work. In [2] is underlined that there is no universally accepted definition of knowledge for mathematics teaching, but nevertheless one can see considerable progress in understanding the domain specific of teachers' knowledge. Shulman $(1985,1987)$ identified $[9 ; 10]$ three categories of teachers' knowledge: subject-matter knowledge, pedagogical content knowledge, and curricular knowledge. According to Shulman, subject-matter or content knowledge is the set of fundamental assumptions, definitions, concepts, and procedures that constitute the ideas to be learned. Pedagogical content knowledge (PCK) includes useful forms of representation of those ideas, powerful analogies, examples, and explanations of a subject, insights into what makes the learning of specific topics easy or difficult, and the conceptions that students of different ages and backgrounds bring with them to the learning of the topic. Curricular knowledge involves understanding how the topics are arranged over time across schooling experiences. Other scholars, such as Fan and Cheong (2002), Kilpatrick, Swafford, \& Findell (2001), and Ma (1999), have introduced related terms to describe aspects of knowledge for teaching mathematics. For instance, Fan and Cheong [11] suggest three aspects of pedagogical knowledge: pedagogical curricular knowledge (knowledge of teaching materials and resources, including textbooks and technology), pedagogical content knowledge (knowledge of ways to represent concepts and procedures); and pedagogical instructional knowledge (knowledge of teaching strategies and classroom organizational models). Kilpatrick, Swafford, \& Findell [12] argued such dimensions of proficiency in school mathematics: conceptual understanding, procedural fluency, strategic competence, adaptive reasoning, and productive disposition. A. H. Schoenfeld, J. Kilpatrick used [13] these dimensions, appropriately modified, to characterize proficient teaching of mathematics: knowing school mathematics in depth and breadth, knowing students as thinkers, knowing students as learners, crafting and managing learning environments, developing classroom norms and supporting classroom discourse as part of "teaching for understanding", building relationships that support learning, reflecting on one's practice.

\subsection{Conceptual Framework}

The TEDS-M framework defined mathematical knowledge for teaching as comprising two main subsets of knowledge: mathematical content knowledge and mathematics pedagogical content knowledge. The last one was considered as mathematical curricular knowledge; knowledge of planning for mathematics teaching and learning (pre-active); and enacted mathematics knowledge for teaching and learning (interactive). This approach formed the basis to questionnaire applied in the TEDS-M investigation. Our questionnaire was similar to the TEDS-M research.

\subsection{Subject Areas}

The tests applied contained subject matter or content tasks and pedagogical (teaching methods) tasks. The ratio was 2:1 consequently.

Four subject areas assessed included number, algebra, geometry and data. Sub-domain numbers included: whole numbers, fractions and decimals, number sentence, patterns and relationships, integers, ratios, proportions, and percent, irrational numbers. Sub-domain algebra included: patterns, algebraic expressions, equations/formulas and functions, calculus and analysis, linear algebra and abstract algebra, number theory. Sub-domain geometry included: geometric shapes, geometric measurement, location and movement. Sub-domain data: data organization and representation, data reading and interpretation, chance.

Framework for the mathematics pedagogical content knowledge included two sub-domains including mathematical curricular knowledge and knowledge for planning mathematics teaching and learning; and knowledge for enacting in mathematics teaching and learning.

The tests for the mathematics pedagogical content knowledge contained questions relating to: selection instructional materials needed for the certain unit or part of a unit; questions to check how teachers select and ground certain strategies when introducing math concepts, facts, algorithm, solving problems; monitoring how students can explain theoretical units; what arguments students give to prove math fact; student's ways of giving a problem's solution; a technique for additional drawing; ways to identify areas of pupil's misunderstanding as well as ways to explain sources of pupil's misunderstanding/.

Since three question formats are used for the TEDS-M questions we also used the same formats: multiple-choice (MC), complex multiple-choice (CMC), and open constructed-response (CR). Each multiple-choice question counts one point toward scores and sub-scores. Complex multiple-choice response items consist of one stem followed by a list of choices, each of which is scored correct or incorrect. Open constructed-response questions are scored from zero up to one, two, or three points, depending on the depth of understanding demonstrated in answering the question. These items include knowledge of students, knowledge of classroom management, knowledge of instructional design, and knowledge of assessment. Most items measure knowledge of theory and about a third of them 
measure knowledge of practice.

Almost every question item was of complex nature requiring some systemic knowledge and skills necessary to answer the question correctly. Given tasks assigned to describe real environment process and phenomena using a math model, including equations, inequalities or using different types of functions, etc. In addition, we note that each separate question in the problem was an independent problem itself.

\subsection{Sub-domain Algebra}

The tasks from the Sub-domain Algebra were aimed at verifying the theoretical training of the future mathematics teachers to teach algebraic component of school mathematics course. The objects evaluated were student's knowledge and skills to:

- use algebraic methods for solving problems;

- find the slope of a tangent line to the graph of $f(x)$ at $x_{0}$; giving relevant arguments,

- apply the appropriate formula for modeling the real problem;

- recognize the situation described by the exponential function;

- find common elements of two arithmetic progressions;

- justify some properties of linear functions;

- identify student knowledge required to prove the roots of a quadratic equation formula;

- establish the truth of the statement relating to matrices in the case when particular operations with matrices are used;

- differentiate the type of a function: logarithmic, exponential, linear, quadratic, trigonometric for modeling dependence described in the problem;

- state the type of a discontinuous of a function at the point;
- $\quad$ set the value at which the quadratic equation with a parameter has digital, rational, irrational, and complex roots;

- be able to predict typical errors in student arguments when proving that the function is continuous at the point;

- recognize different definitions of the function that is continuous at the point.

There were 12 tasks total.

Item assignment to the blocks ensures sufficiently balanced coverage in terms of cognitive domains (knowing, applying, reasoning), number of score points, and mathematics level (novice, intermediate, and advanced). These distributions are shown in Table 1.

Table 1. Distribution of tasks according to the criteria

\begin{tabular}{|c|c|c|c|}
\hline & Knowing (3) & Applying (6) & Reasoning (3) \\
\hline Novice (3) & 3 & $1 \mathrm{~A}$ & \\
\hline Intermediate (5) & 9 & $4 \mathrm{~A}, 6,11 \mathrm{~A}$ & 2,5 \\
\hline Advanced (4) & 12 & 8,10 & 7 \\
\hline
\end{tabular}

For example.

Problem 1A) [7]. The following problems appear in a mathematics textbook for lower secondary school.

1. Peter, David, and James play a game with marbles. They have 198 marbles altogether. Peter has 6 times as many marbles as David, and James has 2 times as many marbles as David. How many marbles does each boy have?

2. Three children Wendy, Joyce and Gabriela have 198 zeds altogether. Wendy has 6 times as much money as Joyce, and 3 times as much as Gabriela. How many zeds does each child have? Solve each problem.

Problem 2 [7]. The graph of the function $y=x+\sin x$

is given below (Fig.1). Determine at which of point A or point $B$ the slope of the graph is greater. Show your work in the box.

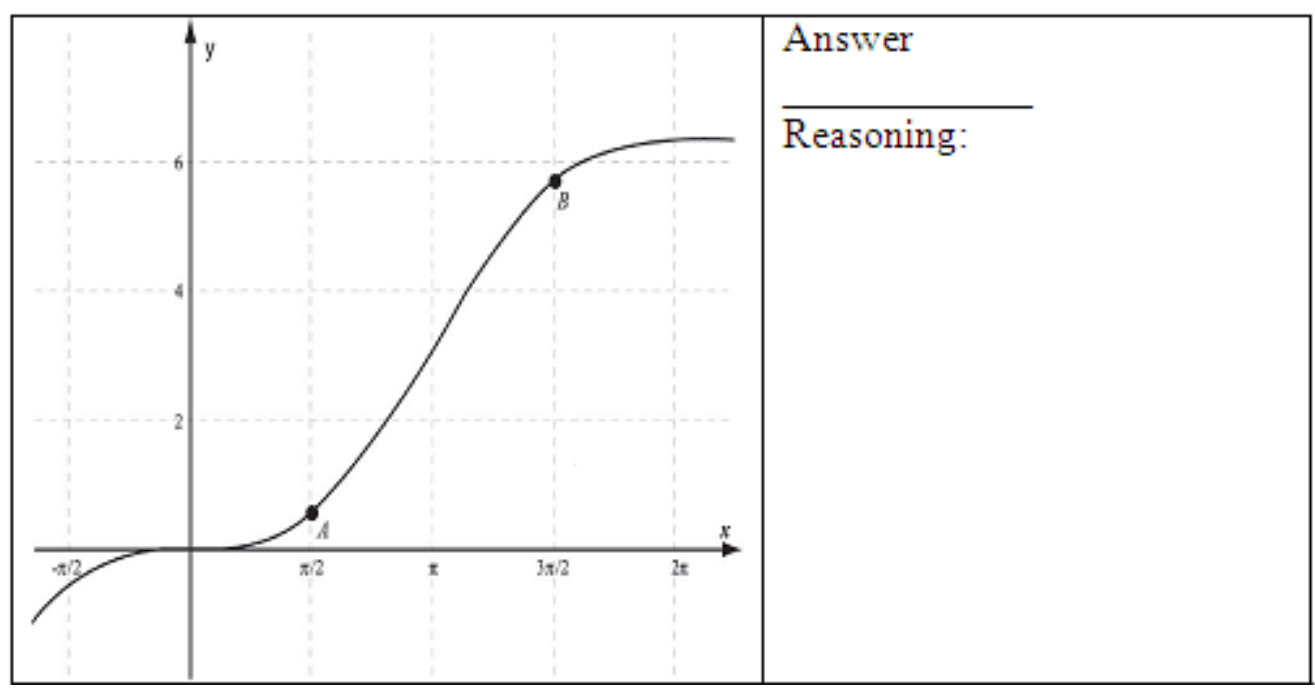

Figure 1. The graph of the function 
Problem 3 [7]. Indicate whether each of the following situations can be modeled by an exponential function. Put a tick in one of the columns of the Table 2.

Table 2. Answers to the problem 3

\begin{tabular}{|c|c|c|c|}
\hline & \multicolumn{1}{|c|}{ Yes } & No \\
\hline A & $\begin{array}{c}\text { The height h of a ball t seconds after it is } \\
\text { thrown into the air. }\end{array}$ & & \\
\hline B & $\begin{array}{c}\text { The amount of money A in a bank after w } \\
\text { weeks, if each week d zeds are put in the bank. }\end{array}$ & & \\
\hline C & $\begin{array}{c}\text { The value V of a car after t years if it } \\
\text { depreciates d \% per year. }\end{array}$ & \\
\hline
\end{tabular}

Problem 4 A) [7]. A teacher gave the following problem to her class. The numbers in the sequence $7,11,15,19$, $23, \ldots .$. increase by 4 . The numbers in the sequence $1,10,19$, $28,37, \ldots$ increase by nine. The number 19 is in both sequences. If the two sequences are continued, what is the next number that is in BOTH the first and the second sequence? What is the correct answer to this problem?

Problem 5 [7]. Prove the following statement: If the graphs of linear functions $f(x)=a x+b \quad g(x)=c x+d$ intersect at a point $P$ on the $x$-axis, the graph of their sum function $f(x)+g(x)$ must also go through $P$.

Table 3. Answers to the problem 6

\begin{tabular}{|c|l|l|l|}
\hline & \multicolumn{2}{|c|}{ Needed } & Not needed \\
\hline A & \multicolumn{1}{|c|}{ How to solve linear equations. } & & \\
\hline B & $\begin{array}{l}\text { How to solve equations of the form } \\
x^{2}=a, a>0\end{array}$ & & \\
\hline C & $\begin{array}{l}\text { How to complete the square of a } \\
\text { trinomial. }\end{array}$ & & \\
\hline D & $\begin{array}{l}\text { How to add and subtract complex } \\
\text { numbers. }\end{array}$ & & \\
\hline
\end{tabular}

Problem 6 [7]. A mathematics teacher wants to show some $<$ lower secondary school $>$ students how to prove the quadratic formula. Determine whether each of the following types of knowledge is needed in order to understand a proof of this result. Put a tick in one of the columns of the Table 3.

Problem 7 [7]. Let $A=\left(\begin{array}{ll}p & q \\ r & s\end{array}\right)$ and $A=\left(\begin{array}{ll}t & u \\ v & w\end{array}\right)$.

Then $A \oplus B$ is defined to be $A \oplus B=\left(\begin{array}{cc}p t & q u \\ r v & s w\end{array}\right)$. Is it true that if $A \oplus B=0$, then either $A=0$, or $B=0$ where 0 represents the zero matrix? Justify your answer.

Problem 8. Your students determine the type of function that models the dependence referred to in the problems.

Problem 1. Under the radioactive decay of some substance $2 \%$ of the substance decomposes per day. Which law does indicate this fact?

Problem 2. The number of forest plantations in forestry at observation period decreased by $2 \%$. Describe the law related to the changes in the amount of wood over the observation period in the forest if the initial stock was $x$ cubic meters. Use the function.

Problem 3. When entering the bacterial environment drug destroys $2.7 \%$ of the bacteria every minute. Which law is related to reduction in the number of bacteria in the environment?

Problem 4. Yeast grows in sugar environment and its mass increases by $3 \%$ per hour. What function could be used to describe the dependence of $t$ on the mass $m$, if the initial weight was 20 grams?

State the type of the corresponding function. Make a mark in each line I the Table 4.

Problem 9. Function $f(x)=(1+x)^{1 / x}$ at the point $x=0$ is (has) ... Put a tick in each line of the Table 5 .

Problem 10. Let your students are proposed to solve a quadratic equation with parameter $a x^{2}+2 x-3=0$ Explore whether its roots belongs to the corresponding numerical set. Put a tick in each line of the Table 6.

Table 4. Answers to the problem 8

\begin{tabular}{|c|l|l|l|l|l|}
\hline & Linear & Quadratic & Logarithmic & Exponential & Trigonometric \\
\hline Problem 1. & & & & & \\
\hline Problem 2. & & & & & \\
\hline Problem 3. & & & & & \\
\hline Problem 4. & & & & & \\
\hline
\end{tabular}

Table 5. Answers to the problem 9

\begin{tabular}{|c|c|c|c|}
\hline & & Yes & No \\
\hline A & has the removable gap of the first kind & & \\
\hline B & has irremovable gap of the first kind & & \\
\hline C & has the gap of the second kind & & \\
\hline D & has a vertical asymptote. & & \\
\hline E & hentinuous & & \\
\hline
\end{tabular}


Table 6. Answers to the problem 10

\begin{tabular}{|c|l|l|l|l|}
\hline & $a \in\{1\}$ & $a \in\{1 ; 2\}$ & $a \in(1 ; 2)$ & $a \in(-4 ;-3)$ \\
\hline $\begin{array}{c}\text { All the roots of } \\
\begin{array}{c}2 x^{2}+2 x-3=0 \\
\text { are integers if } \ldots\end{array}\end{array}$ & & & \\
\hline $\begin{array}{c}\text { All the roots of } \\
a x^{2}+2 x-3=0 \\
\text { are rational numbers if... }\end{array}$ & & & & \\
\hline $\begin{array}{c}\text { Some roots of } \\
a x^{2}+2 x-3=0 \\
\text { are irrational numbers if }\end{array}$ & & & & \\
\hline $\begin{array}{c}\text { All roots of } \\
a x^{2}+2 x-3=0 \text { are } \\
\text { complex numbers if ... }\end{array}$ & & & & \\
\hline
\end{tabular}

Problem 11 A) Illustrating the "trigonometric form of the complex number" the teacher gave examples and counterexamples to this concept. Determine which of the following items illustrate examples, and which items illustrate counterexamples. Make a mark in each line of the Table 7.

Problem 12. You need to prove the statement: "The function $y=x^{2}$ is continuous throughout in accordance to definition" Determine which proof is mathematically correct. Make only one mark in each line of the Table 8.

Table 7. Answers to the problem $11 \mathrm{~A}$ )

\begin{tabular}{|l|c|l|l|}
\hline & & Example & Counterexample \\
\hline A & $-\sqrt{2}\left(\sin \frac{\pi}{3}+i \cos \frac{\pi}{3}\right)$ & & \\
\hline B & $\sqrt{2}\left(\sin \frac{\pi}{3}+i \cos \frac{\pi}{3}\right)$ & & \\
\hline C & $\sqrt{2}\left(\cos \frac{\pi}{3}-i \sin \frac{\pi}{3}\right)$ & & \\
\hline D & $\sqrt{2}\left(\cos \frac{\pi}{3}+i \sin \frac{\pi}{3}\right)$ & & \\
\hline
\end{tabular}

Table 8. Answers to the problem 12

\begin{tabular}{|l|l|l|l|}
\hline & & Yes & No \\
\hline A & $\begin{array}{l}\text { Function } y=x^{2} \text { is defined for every real value of } x \text {, and therefore it is } \\
\text { continuous in for every real value of } x \text { in accordance to definition }\end{array}$ & & \\
\hline B & $\begin{array}{l}\text { We apply function graph (Fig. 2). As we see, there are } \\
\text { no points of discontinuous thus function is continuous } \\
\text { for all real values of } x \text { in accordance to definition } \\
\text { of the function }\end{array}$ & $\begin{array}{l}\text { Let provide growth to argument }(\Delta x) \text {, and find the corresponding increment of } \\
\text { the function }(\Delta y) . \text { Then let verify that the growth function is infinitesimal, } \\
\text { provided that the increase in the argument tends to } 0 .\end{array}$ & \\
\hline D & $\begin{array}{l}\text { The function } y=x^{2} \text { is the product of two continuous functions thus it is } \\
\text { continuous for any valid value of } x\end{array}$ & & \\
\hline
\end{tabular}

\subsection{Analysis of the Data}

Assessment objects and the number of students (S) and teachers $(\mathrm{T})$ who correctly completed the task (in \%) are shown in Table 9

Accordingly, the performance results presented in the table (Table 9) reveal that students show significant results when they apply algebraic approach to solve text problems, or apply a derivative to study and build function graph, when students apply basic concepts and facts relating to arithmetic and geometric progression to solve problems. However, testing has shown that $66.3 \%$ of students and $76 \%$ of young teachers experience significant difficulties in mathematic modeling the real situation with an equation or function. We found insufficient level of student's and young teachers' readiness to develop students' knowledge about function that is continuous at the point: $81.8 \%$ find it difficult to explain if the function is continuous at the point applying different definitions, $80.7 \%$ experience difficulties to establish the type of discontinuous function at the point. Almost $98.6 \%$ of young teachers failed to recognize common errors in students' proof of the fact that function is continuous at the 
point. Although the problems in solving linear and quadratic equations weren't found, only $39.7 \%$ of surveyed students could properly establish a certain numerical set that the quadratic equation root belongs to depending on the setting. Teachers were more successful with this task - $76 \%$ gave the correct answer.

Table 9. Students and teachers' performance results for Algebra test tasks.

\begin{tabular}{|c|c|c|c|}
\hline \multirow{2}{*}{$\#$} & \multirow{2}{*}{ Assessment objects } & \multicolumn{2}{|c|}{ Performance results } \\
\hline & & $\mathrm{S}$ & $\mathrm{T}$ \\
\hline $1 \mathrm{~A}$ & $\begin{array}{l}\text { Using the well-known algebraic methods } \\
\text { for solving text problems }\end{array}$ & $88,9 \%$ & $96 \%$ \\
\hline 2 & $\begin{array}{l}\text { Finding the slope of the graph of the } \\
\text { function, reasoning the answer }\end{array}$ & $71,9 \%$ & $60 \%$ \\
\hline 3 & $\begin{array}{l}\text { Mathematics modeling, applications of } \\
\text { exponential function for description } \\
\text { some situation }\end{array}$ & $33,7 \%$ & $24 \%$ \\
\hline $4 \mathrm{~A}$ & $\begin{array}{l}\text { Finding common elements of two } \\
\text { arithmetic progressions }\end{array}$ & $50,2 \%$ & $76 \%$ \\
\hline 5 & $\begin{array}{l}\text { Assertions justification related to the } \\
\text { properties of linear functions. }\end{array}$ & $35,9 \%$ & $10 \%$ \\
\hline 6 & $\begin{array}{l}\text { Identification of knowledge needed to } \\
\text { prove the quadratic equation root formula }\end{array}$ & $76,9 \%$ & $72 \%$ \\
\hline 7 & $\begin{array}{l}\text { Validity check of statement related to } \\
\text { matrices when particular matrices } \\
\text { operations are used }\end{array}$ & $31,4 \%$ & $20 \%$ \\
\hline 8 & $\begin{array}{l}\text { Modeling the situation described in the } \\
\text { problem with logarithmic, exponential, } \\
\text { linear, quadratic, trigonometric functions. }\end{array}$ & $25,4 \%$ & $36 \%$ \\
\hline 9 & $\begin{array}{l}\text { Setting the type of discontinuous function } \\
\text { at the point }\end{array}$ & $19,3 \%$ & $8 \%$ \\
\hline 10 & $\begin{array}{l}\text { Solving quadratic equations with a } \\
\text { parameter, setting parameter values at } \\
\text { which the equation has integer, rational, } \\
\text { irrational, and complex roots }\end{array}$ & $39,7 \%$ & $76 \%$ \\
\hline $\begin{array}{l}11 \\
\mathrm{~A}\end{array}$ & $\begin{array}{l}\text { Giving examples and counterexamples to } \\
\text { the concept "trigonometric form of the } \\
\text { complex number" }\end{array}$ & $80,5 \%$ & $34 \%$ \\
\hline 12 & $\begin{array}{l}\text { Recognizing common students' } \\
\text { mistakes in the prof if the function is } \\
\text { continuous at the point using different } \\
\text { definitions }\end{array}$ & $18,2 \%$ & $1,4 \%$ \\
\hline
\end{tabular}

\section{Conclusions}

The analysis of the current state in the Ukrainian mathematics teacher training identified some contradictions. On the one hand the modern requirements for Mathematics teacher's professional competences are very high, especially for their knowledge and skills for mathematics teaching. On other hand the research reveals that Ukrainian prospective teachers are ill prepared for performing some kinds of mathematic and teaching activities. The identified contradictions require the ways to improve the current methodology of future mathematics teacher training. In future articles we plan to focus on methodology and tests results that reflect other aspects of the study.

\section{Acknowledgements}

We would like to thank the authors of the references who have helped us indirectly through their books, journals while preparing this manuscript.

\section{REFERENCES}

[1] G. S. Kovaleva, L. O. Denyshcheva, T. A. Koreshkova, Y. A. Semeniachenko, N. V. Sheveliova. Report about Research on the theme: «The Quality of Pedagogical Education in Russia (according to the International Investigation of Study of Pedagogical Education and Estimation of Preparation Quality of Future Mathematics Teachers TEDS»(Final), Moscow, B.M.I., 2010, 174.

[2] M. T. Tatto, J. Schwille, S. Senk. Teacher Education and Development Study in Mathematics (TEDS-M): Policy, practice, and readiness to teach primary and secondary mathematics. Conceptual framework, East Lansing, MI: Teacher Education and Development International Study Center, College of Education, Michigan State University, USA, 2008. Online available from http://teds.educ.msu.edu

[3] M. T. Tatto, J. Schwille, S. Senk, K. Bankov, M. Rodriguez, M. Reckase, L. Ingvarson, R. Peck, R. Rowley. The Mathematics Preparation of Future Primary and Secondary Teachers: Policy, Opportunities to Learn, Knowledge and Beliefs. International Report, Teacher Education and Development International Study Center, College of Education, Michigan State University, 2011.

[4] M. T. Tatto, J. Schwille, S. L. Senk, L. Ingvarson, G. Rowley, R. Peck, M. Bankov, M. Rodriguez, M. Reckase. Policy, practice, and readiness to teach primary and secondary mathematics in 17 countries: Findings from the IEA Teacher Education and Development Study in Mathematics (TEDS-M). Amsterdam, the Netherlands: International Association for the Evaluation of Educational Achievement (IEA), 2012.

[5] D. Burghes. International comparative study in mathematics teacher training research program with the Centre for Innovation in Mathematics Teaching (CIMT). Enhancing the training of teachers of mathematics, Copyright CfBT, 2011, Online available from http://www.cimt.plymouth.ac.uk/papers/icsmtt.pdf

[6] R. Even, D.L. Ball (Eds.). The Professional Education and Development of Teachers of Mathematics: The 15th ICMI Study. New CMI Study Series, New York, NY: Springer, 2009.

[7] Released Items Future Teacher Mathematics Content Knowledge (MCK) and Mathematics Pedagogical Content Knowledge (MPCK) - Secondary TEDS-M International Study Center, Michigan State University, East Lansing, USA, 2011, Online available from http://teds.educ.msu.edu/reports/

[8] N. A. Tarasenkova, I. A. Akulenko. Determination of Students' Beliefs is one of the Aspects of Competence Oriented System of Mathematics Teachers' Methodical Preparation. American Journal of Educational Research 1, no. 11, 2013, 477-483.

[9] L. S. Shulman. Those who understand: Knowledge growth in teaching. Educational Researcher, no 15(2), 1986, 4-31. 
Online available from

http://coe.utep.edu/ted/images/academic_programs/graduate/ $\mathrm{pdfs} /$ matharticles/Knowledge\%20Growth\%20in\%20Teachin g\%20Shulman.pdf

[10] L. S. Shulman. Knowledge and teaching: Foundations of the new reform. Harvard Educational Review, 1987, no 57(1), $1-22$.

[11] L. Fan, N. P. Cheong. Investigating the sources of Singaporean mathematics teachers" pedagogical knowledge. In D. Edge, \& Yeap, B. H. (Eds.), Proceedings of Second East
Asia Regional Conference on Mathematics Education and Ninth Southeast Asian Conference on Mathematics Education, 2002, Vol. 2, 224-231.

[12] J. Kilpatrick, J. Swafford, \& B. Findell (Eds.). Adding it up: Helping children learn mathematics. Washington, DC: National Academy Press, 2001.

[13] A. H. Schoenfeld, J. Kilpatrick. Toward a theory of proficiency in teaching mathematics. Online available from $\mathrm{http}: / /$ vocserve.berkeley.edu/faculty/ahschoenfeld/Schoenfel d_Teaching_Proficiency.pdf 